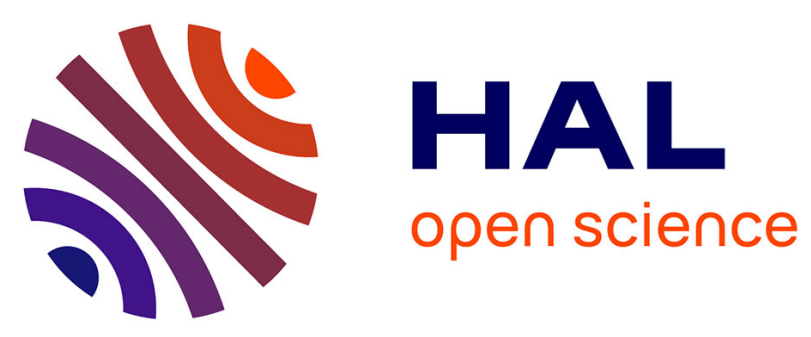

\title{
The European MP-Tandems
}

S.J. Skorka

\section{To cite this version:}

S.J. Skorka. The European MP-Tandems. Revue de Physique Appliquée, 1977, 12 (10), pp.1279-1290. 10.1051/rphysap:0197700120100127900 . jpa-00244310

\section{HAL Id: jpa-00244310 https://hal.science/jpa-00244310}

Submitted on 1 Jan 1977

HAL is a multi-disciplinary open access archive for the deposit and dissemination of scientific research documents, whether they are published or not. The documents may come from teaching and research institutions in France or abroad, or from public or private research centers.
L'archive ouverte pluridisciplinaire HAL, est destinée au dépôt et à la diffusion de documents scientifiques de niveau recherche, publiés ou non, émanant des établissements d'enseignement et de recherche français ou étrangers, des laboratoires publics ou privés. 


\title{
THE EUROPEAN MP-TANDEMS
}

\author{
S. J. SKORKA \\ University of Munich, \\ 8046 Garching, Germany
}

\begin{abstract}
Résumé. - Depuis la dernière conférence des Tandems en 1973, les laboratoires MP de Heidelberg, Orsay et Strasbourg ont augmenté les performances de leurs machines en utilisant des tubes en acier inoxydable HVEC 14" et Munich a installé un tube céramique titane NEC. Ces quatre machines sont maintenant isolées avec du SF 6 à $100 \%$. En dehors de cela les programmes de conversion de tous ces laboratoires comprennent des mesures diverses qui conduisent à améliorer la stabilité en tension, les propriétés des faisceaux d'ions lourds et la transmission, avec des vies moyennes des composantes améliorées ou avec moins de dommages dus aux étincelles. En particulier à Heidelberg et Munich la courroie a été remplacée par des chaînes de Pelletron.

On présente une revue des performances caractéristiques des machines converties et certains problèmes particuliers sont discutés.

Abstract. - Since the last Tandem conference in 1973 the MP laboratories at Heidelberg, Orsay and Strasbourg have upgraded their machines utilizing HVEC 14" stainless steel tubes, and Munich has installed NEC titanium ceramic tubes. All four machines are now insulated by $100 \% \mathrm{SF}_{6}$. Beyond that, the conversion programmes of all laboratories included various other measures aiming at improved voltage stability, heavy ion beam properties and transmission, at better component lifetimes or at reduced spark damage rates. In particular, at Heidelberg and Munich the charging belt was replaced by Pelletron chains.

Actual performance characteristics of the converted machines and operating experiences are reviewed and some of their special features and problems are discussed.
\end{abstract}

1. Introduction. - The somewhat disappointing performance of the standard $10 \mathrm{MV}$ MP Tandem as compared to the EN and FN Tandems is a good example of the difficulties encountered with increasing size and stored energy of electrostatic accelerators, and has evoked a lot of effort in many MP Tandem laboratories and at HVEC, aiming at improved operation characteristics and improved component life times. During these efforts - called upgrading program - a lot of experience was collected, most of it after the last Tandem conference four years ago at Daresbury.

The original MP Tandem was designed primarily for the acceleration of light particles. With the increasing interest in heavy ion beams additional improvements apart from higher terminal voltages became desirable. Consequently the upgrading programs included other features like terminal pumping, terminal focussing, increased stripper foil capacity, double stripping, improved low energy vacuum, and other measures to improve the heavy ion performance.

In this paper the experiences of the european MP Tandem laboratories with their upgraded accelerator and some of the features of their machines are reviewed.

2. The European MP Tandems. - Table I summarizes some important data on the four european
Tandems. All four machines were upgraded, the two french ones already since more than two years, Heidelberg in several steps the last one finished february 76 and Munich since the beginning of this year.

While the german machines still have difficulties to run at $13 \mathrm{MV}$, Orsay and Strasbourg are operating up to $13 \mathrm{MV}$ according to the wishes of the experimentalists.

The relatively low yield of beam time at Orsay is caused mainly by budget limitations, not so much by technical difficulties. The total running time above 12.5 MV at Orsay is remarkable.

While Pelletron charging chains were installed in MP5 and 8 the other two are still using belts with considerable life time problems. The average life time of the belts, installed after upgrading is at Strasbourg and Orsay only around $1500-2500 \mathrm{~h}$, in spite of efforts to improve the belt charging systems and the configuration of the guiding bars. More details of the charging systems are discussed in separate papers submitted to this conference.

The terminal stabilities listed in table I are those observed with operating beam feedback stabilization.

With increasing use of heavy ions number and quality of stripper foils are becoming more important. A gas stripper can only be used if adequate pumping at the terminal is available. The penetration of only a 
TABLE I

Summary of important data on the upgraded european MP Tandems

\begin{tabular}{|c|c|c|c|c|}
\hline & $\begin{array}{c}\text { MP 5 } \\
\text { Heidelberg } \\
-\end{array}$ & $\begin{array}{l}\text { MP 8 } \\
\text { Munich } \\
-\end{array}$ & $\begin{array}{l}\text { MP } 9 \\
\text { Orsay }\end{array}$ & $\begin{array}{c}\text { MP } 10 \\
\text { Strasbourg } \\
-\end{array}$ \\
\hline upgraded since & feb. 76 & jan. 77 & jan. 75 & jan. 75 \\
\hline upgraded since $(h)$ & 10800 & 3000 & 20000 & 20000 \\
\hline terminal at high voltage $(\mathrm{h})$ & 8300 & 2200 & 11000 & 14300 \\
\hline available for experiment (h) & 6000 & 1500 & 7000 & 12800 \\
\hline voltage above $12.5 \mathrm{MV}(\mathrm{h})$ & 50 & 20 & 2000 & 750 \\
\hline charging system & Pelletron & Pelletron & belt & belt \\
\hline terminal stability (kVpp) & 0.4 & 0.6 & $2-3$ & $2-2.5$ \\
\hline terminal stripper foils & 228 & 228 & 120 & 120 \\
\hline gas stripper & yes & no & not used & yes \\
\hline 2. foil stripper & yes & no $(3)$ & no & yes \\
\hline $\mathrm{SF}_{6}$ pressure (bar) & 7.2 & 7.5 & 7.6 & $6.0(1)$ \\
\hline resistors $\mathrm{M} \Omega /$ elements & $400 / 20$ & $800 / 40$ & $400 / 40$ & $400 / 40$ \\
\hline pumps (base) & $\mathrm{TM}$ & IG & TM & $\mathrm{TM} / \mathrm{LN}_{2}$ \\
\hline pumps (terminal) & cryo & IG & cryo $(2)$ & cryo \\
\hline tube vacuum $\left({ }^{4}\right)\left(\times 10^{-7}\right.$ torr $)$ & $1-3$ & $0.05-0.1$ & $1-4$ & $1-3$ \\
\hline
\end{tabular}

( $\left.{ }^{1}\right)$ With $10 \%$ air, $\left({ }^{2}\right)$ not yet in use, $\left({ }^{3}\right)$ to be installed, $\left({ }^{4}\right)$ measured at LE and HE base.

small part of the stripper gas into the low energy tube would affect the heavy ion transmission. The reduced average charge state as compared to the foil stripper makes gas stripping unattractive for heavier ions, except in connection with double stripping.

All machines are insulated by pure $\mathrm{SF}_{6}$ and all of them are equipped with HVEC high gradient resistors. At Munich a separate potential grading of the tubes by corona tubes is provided. Munich is using NEC titanium ceramic tubes while the other MP's are operated with HVEC 14" stainless steel glass tubes.

Mercury diffusion pumps were eliminated at all four Tandems in order to reduce oil contaminations in the vacuum. Strasbourg is still using a liquid nitrogen cool trap. At Heidelberg some traces of turbomolecular - and forepump - oil were detected on the cold finger of the terminal cryopumps indicating the limitations of TM-pumps with respect to oil free vacuum.

The very good vacuum at Munich is due to the titanium ceramic tubes which are bonded by aluminium and are bakable. The pumping speed of the base pumps is only $400 \mathrm{l} / \mathrm{s}$ each. The basic vacuum of the other machines is about $1 \times 10^{-7}$ torr. If quenching gas is used to reduce the tube activity above 11 or $12 \mathrm{MV}$ the vacuum rises to the values indicated in the table with the consequence of clearly noticeable reductions of heavy ion transmissions.

In table II some data on a few selected beams used at the four laboratories during experiments are compiled to illustrate what can be done with the upgraded machines. It should be mentioned that Munich still has difficulties at the higher voltages which will be discussed later. Note that the beam currents are in particle nanoamperes.

Table II shows that heavy ion energies reach from 90-180 MeV and currents are in the 2-200 pnA region, partly limited by targets or counting rate problems, partly by ion source or transmission problems and partly by stripper foil life times. Beam loading of the accelerator is observed nowhere at injected beams around a few microamperes. The sputter source allows such exotic beams like ${ }^{28} \mathrm{Si}$ or ${ }^{24} \mathrm{Mg}$ at considerable intensities. Also the ${ }^{48} \mathrm{Ca}$ is remarkable. The value of double stripping is clearly indicated. Gold beams at a charge state lower than $13^{+}$exceed the mass energy product of the analysing magnet above about $10 \mathrm{MV}$ terminal voltage. The most probable charge state at this voltage lies between $9^{+}$and $10^{+}$.

With the improved voltage performance of the upgraded accelerators and the improved ion characteristics the flexibility of the MP-Tandem is greatly increased. The distribution of the experimental time as a function of terminal voltage and the distribution of the various accelerated ion beams are partly determined by the experimental program, partly by accelerator difficulties.

As mentioned above, at Orsay the machine has been running above $12.5 \mathrm{MV}$ at nearly $30 \%$ of the time. A recent average is even much higher. Figure 1 presents a graph of the distribution of running time plotted against terminal voltage for Strasbourg. According to the experimental program it is peaked around $10 \mathrm{MV}$. On figure $2 \mathrm{a}$ similar plot is shown for Heidelberg. Here the experiments call for the highest possible energies, which are limited by the increasing risk of damages with increasing terminal voltage.

3. $\mathbf{S F}_{6}$ insulation and spark damages. - During their upgrading several laboratories have carried out high voltage tests without tubes to explore the terminal to tank and the column insulation. On figure 3 the terminal to tank breakdown voltage is plotted as a 


\section{TABLE II}

Some selected heavy ion beams used at the european MP Tandem laboratories for actual experiments

$\begin{array}{lccccc} & \begin{array}{c}\text { Terminal } \\ \text { voltage }\end{array} & \begin{array}{c}\text { Ion } \\ \text { species }\end{array} & \begin{array}{c}\text { Beam } \\ \text { energy } \\ \text { MeV }\end{array} & \begin{array}{c}\text { Beam } \\ \text { current } \\ \text { pnA }\end{array} & \begin{array}{c}\text { Charge } \\ \text { state }\end{array} \\ & - & - & - & - & - \\ \text { Heidelberg } & 12.3 & 58 \mathrm{Ni} & 147 * & 9 & 6+/ 13+ \\ & 13.0 & 32 \mathrm{~S} & 156 & 3 & 11+ \\ & 12.2 & 28 \mathrm{Si} & 135^{*} & 80 & 7+/ 12+ \\ \text { Munich } & 13.0 & 16 \mathrm{O} & 91 & 200 & 6+ \\ & 10.3 & 197 \mathrm{Au} & 144 & 2 & 13+ \\ & 10.0 & 48 \mathrm{Ca} & 90 & 20 & 8+ \\ & 10.0 & 40 \mathrm{Ca} & 131 & 2 & 11+ \\ \text { Orsay } & 10.4 & 18 \mathrm{O} & 73 & 13 & 6+ \\ & 13.0 & 40 \mathrm{Ca} & 156 & 2 & 11+ \\ & 13.0 & 34 \mathrm{~S} & 130 & 9 & 9+ \\ & 13.0 & 32 \mathrm{~S} & 130 & 150 & 9+ \\ \text { Strasbourg } & 13.0 & 18 \mathrm{O} & 91 & 200 & 6+ \\ & 13.15 & 32 \mathrm{~S} & 185^{*} & 7 & 10+/ 14+ \\ & 13.0 & 32 \mathrm{~S} & 143 & 40 & 10+ \\ & 12.5 & 24 \mathrm{Mg} & 125^{*} & 3 & 6+/ 10+ \\ & 12.6 & 24 \mathrm{Mg} & 76 & 12 & 5+\end{array}$

* Using double stripping.

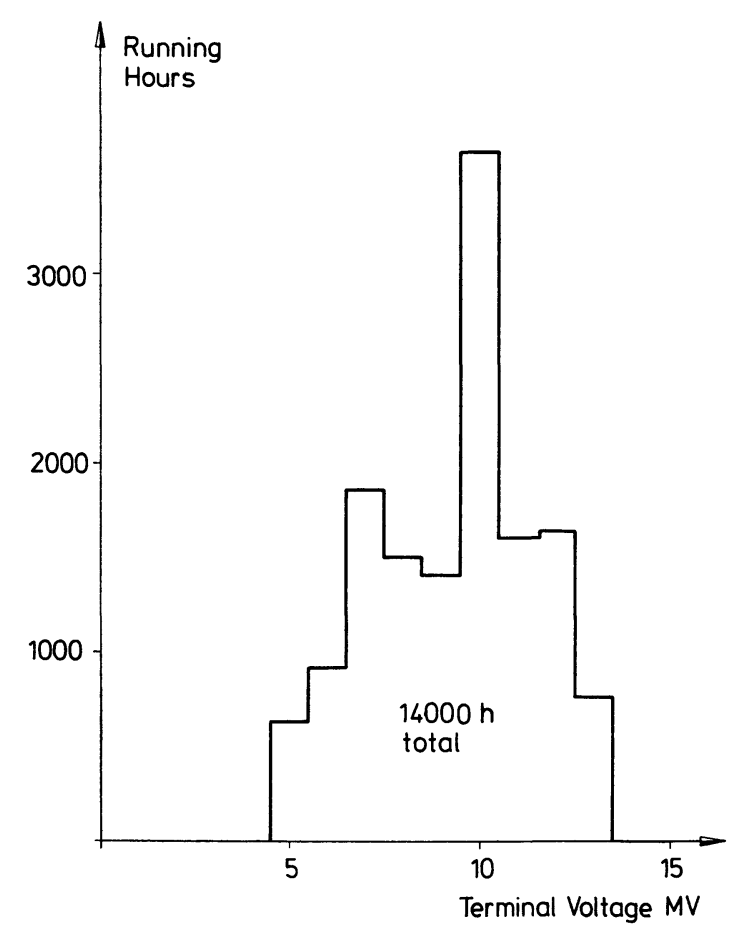

FIG. 1. - Experimental running time as a function of terminal voltage for MP-10 Strasbourg. The distribution is peaked at $10 \mathrm{MV}$ according to the experimental program.

function of $\mathrm{SF}_{6}$ pressure. Some of the data were already shown at the Daresbury conference. It is interesting to see that the data are following a simple relation as shown. Similar relations were found at Daresbury for smaller spark gaps [1]. The larger the size of the electrodes, the smaller the exponent of $p$.

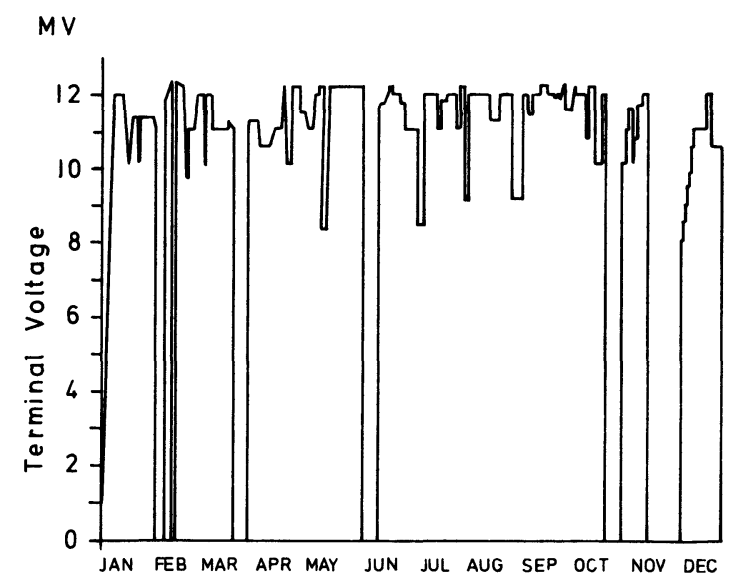

FIG. 2. - Running record of MP-5 Heidelberg for 1976. Experiments were limited by difficulties of the accelerator at above $12.3 \mathrm{MV}$.

Assuming a cylindrical field between smooth electrodes one would theoretically expect the straight line defined by the equality of the gas multiplication and the electron attachment coefficient.

In practice the fine structure of the column leads to field enhancements. The size effect just mentioned reduces the breakdown voltage further. If dust particles are present the otherwise monotonically increasing curve does bend down at high pressures. Particularly small metallic particles are extremely effective in triggering tank sparks.

Figure 4 reproduces a calculation done at Daresbury and published already during the Daresbury conference [2] just to show how large the field 


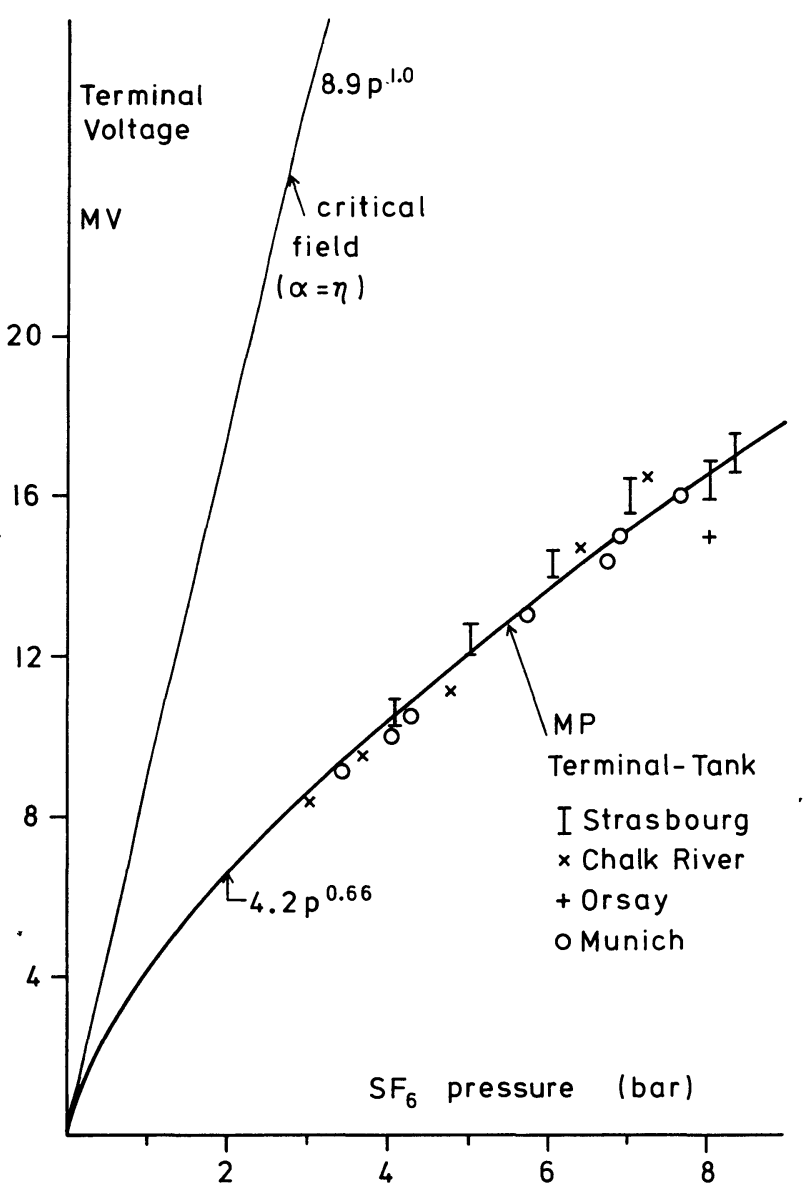

Fig. 3. - Terminal to tank breakdown characteristic for MP tandems. The corresponding curve for the dc-breakdown of the column and tube spark gaps lies about $50 \%$ - $60 \%$ higher.

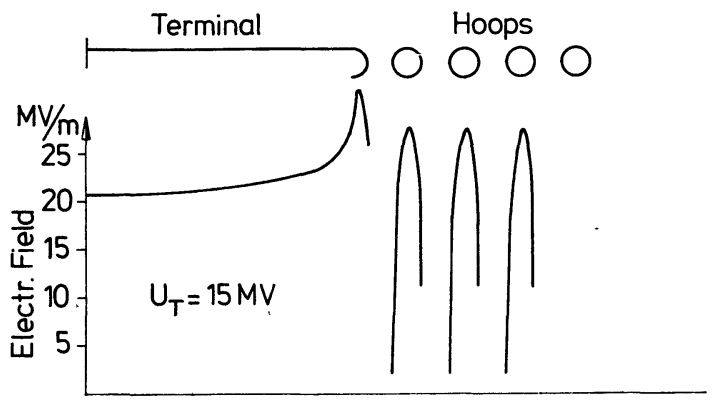

Fig. 4. - Calculated field enhancement due to terminal and column structure for the MP tandem according to Rabinowitz (Ref. [2]).

enhancements are due to an improper shape of the terminal and due to the small size of the hoops. The smooth-electrode field would be $15 \mathrm{MV} / \mathrm{m}$, the enhancement is a factor of two.

Tank sparks, but also column or tube sparks carry the risk of damages. To prevent or at least reduce sparks is extremely important. The tank spark rate is determined mainly by the hygiene in the tank (dust, water, $\mathrm{SF}_{6}$-breakdown products and other impurities, ring alignment, electrical contacts, surface conditions etc.) and by the conditioning status of the tube. A reduction of the spark rate reduces the damage rate and hence the number of tank openings. The amount of transported dust again reduced hereby, feeds back favourably into the spark rate.

On figure 5 spark rates as observed at Orsay are plotted. The spark rate decreased by one order of magnitude during the period of time after upgrading was completed. The relatively low spark rate of less than one spark per day might be connected to the successful running statistics mentioned above. Orsay reports only a few very small tracks in the glass of the column, no Lichtenberg figures, no other damages, no broken glass inside the tube except 2 relatively small fractures, and only one resistor failure after $10000 \mathrm{~h}$ of running.

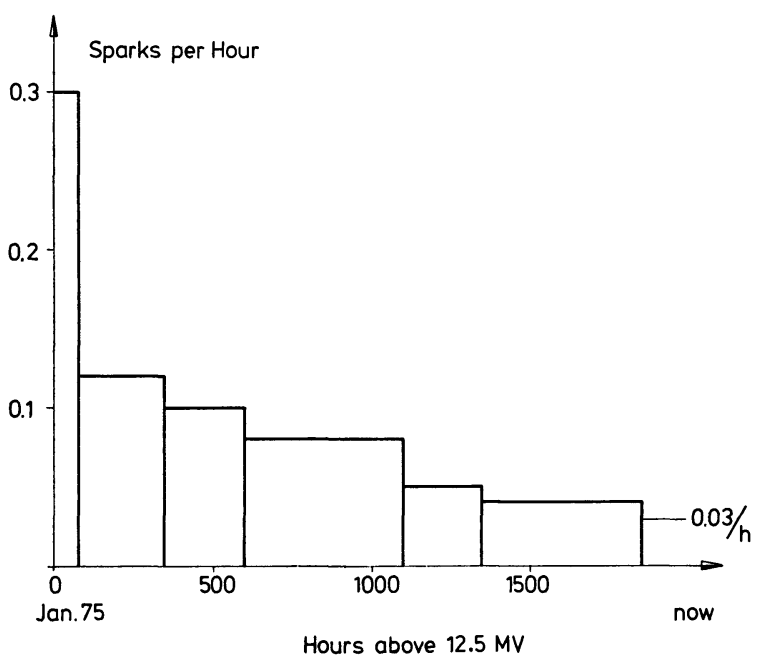

Fig. 5. - Spark rate per hour as a function of running hours above 12.5 MV for MP-9 Orsay.

A close correlation between spark rate and tube activity (spikes of the vacuum, the radiation level, the column current and the terminal voltage) under otherwise clean conditions has been observed definitely at Orsay, Strasbourg and Heidelberg. As soon as quenching gas is used to reduce the tube spiking the spark rate goes down as well. The decreasing spark rate on figure 5 reflects at least partly the slow improvement of the conditioning status of the tube, and partly the improved cleanness in the tank.

In spite of the successful operation of at least part of the upgraded MP's at $13 \mathrm{MV}$ it should be kept in mind - and all MP users do so - that this machine is in a marginal condition if operated near $13 \mathrm{MV}$. Particularly at Heidelberg considerable damages in the column glass and tubes were recorded.

Figure 6 shows a photograph of column glass badly damaged by many fractures penetrating several $\mathrm{mm}$ into the glass and extending over three sections. At least 40 other glasses show similar damages never at regions with protruding polyvinylacetate glue. Some column glass damage although much less than at 


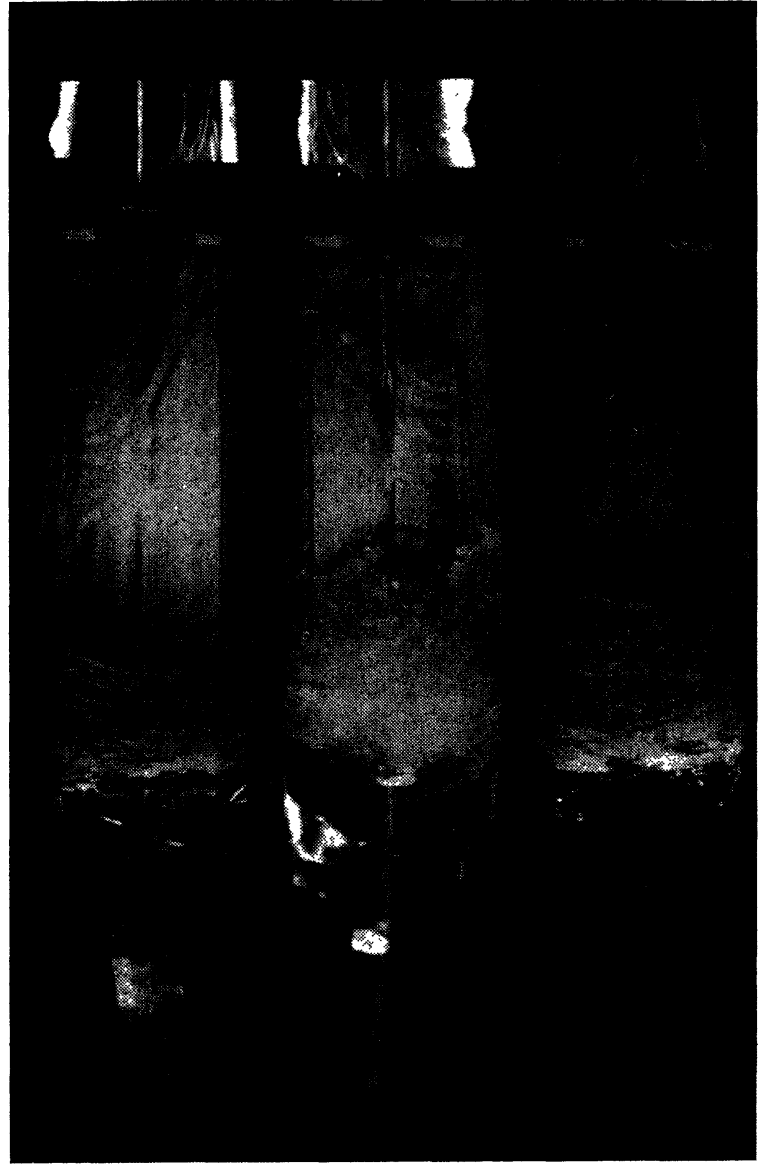

FIG. 6. - Spark damage of column glass of MP-5 Heidelberg. The region of shattered glass extends several mm deep.

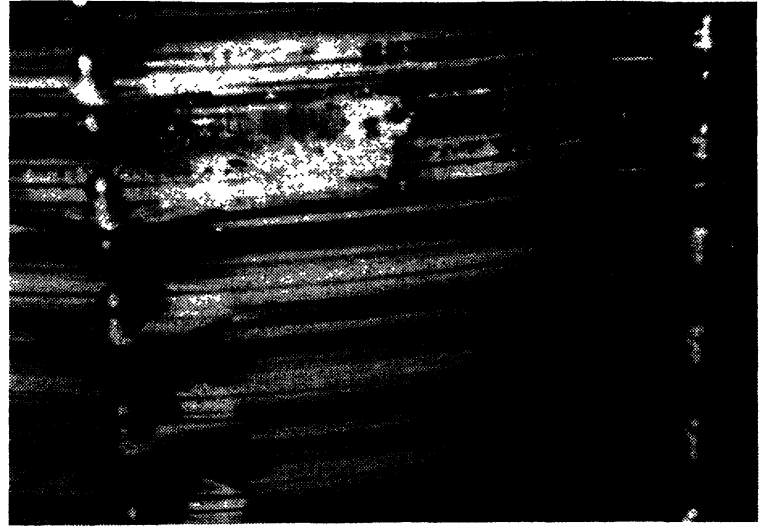

Fig. 7. - Tube section 3 of MP-5 Heidelberg. One glass insulator shows a larger damaged region eroded by repeated breakdowns.

Heidelberg was also observed at the other european MP's.

In addition three of the eight tube sections broke down at Heidelberg. These breakdowns were the first and only ones so far observed of all 48 tubes now in use all over the world.

The figures 7 and 8 show photographs of the damages of the number 3 section. Over about $90^{\circ}$ the glass between the grooves on the inside has come off. By many successive breakdowns through the volume, the glass was damaged over a larger region also on the outside as seen on figure 8. A small track in one of the tube glasses also observed at Heidelberg is seen on the photograph figure 9.

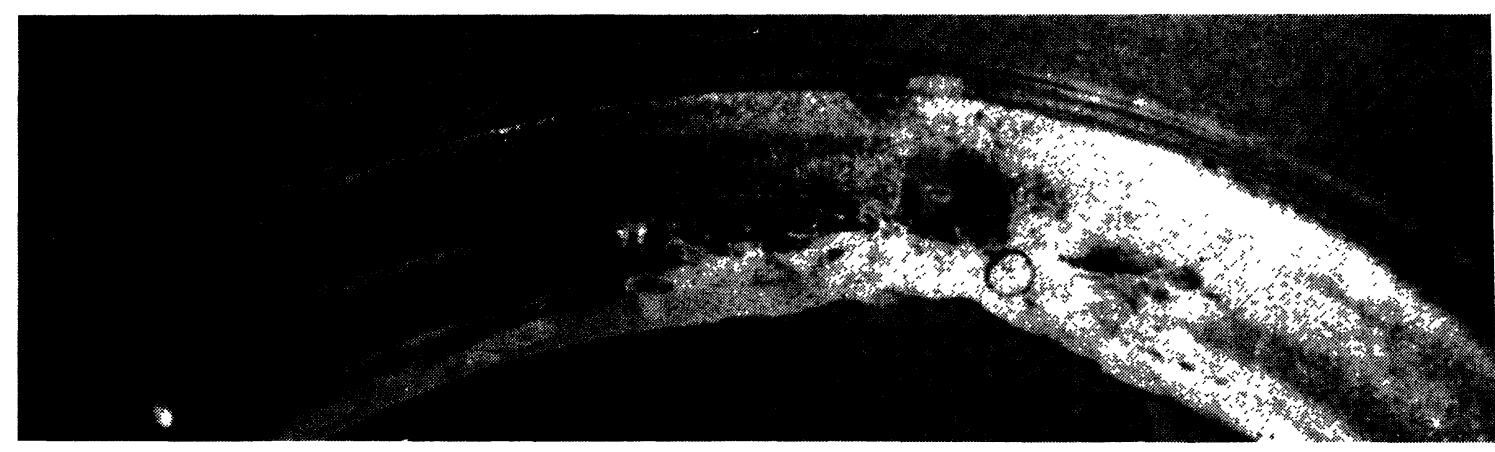

FIG. 8. - Damaged glass insulator (same as in Fig. 7), electrode removed. Circled: the point where the actual electrical puncture occured, about $8 \mathrm{~mm}$ from the inner edge of the seal.

Why is there so much damage in the Heidelberg MP? Heidelberg has also lost a great deal of the column resistors while the other MP's had only few losses. The machine is operated as carefully as the other ones, even more conservatively after the first appearance of extraordinary damages.

At the early phases of their upgrading programs the Heidelberg and Munich MP's were insulated by a mixture of $\mathrm{SF}_{6}$. Heidelberg used $23 \%$ of $\mathrm{SF}_{6}$ mixed to the usual $\mathrm{N}_{2} / \mathrm{CO}_{2}$ gas, while Munich tried a $30 \% \mathrm{SF}_{6}$ fraction in $\mathrm{N}_{2}$. The pressures were about 12 bar. At
Munich it was impossible with this mixture to exceed 13.5 MV terminal voltage during the tests without tubes. The corresponding tests at Heidelberg had only slightly better results. After conversion to pure $\mathrm{SF}_{6}$ a much reduced damage rate of column resistors was observed at Munich under otherwise comparable conditions [3]. It was concluded from this very distinct effect that pure $\mathrm{SF}_{6}$ apparently provides some extra protection due to a more favorable energy dissipation or reduced overvoltages or rise times.

Even if insulated by pure $\mathrm{SF}_{6}$ the MP has to be 


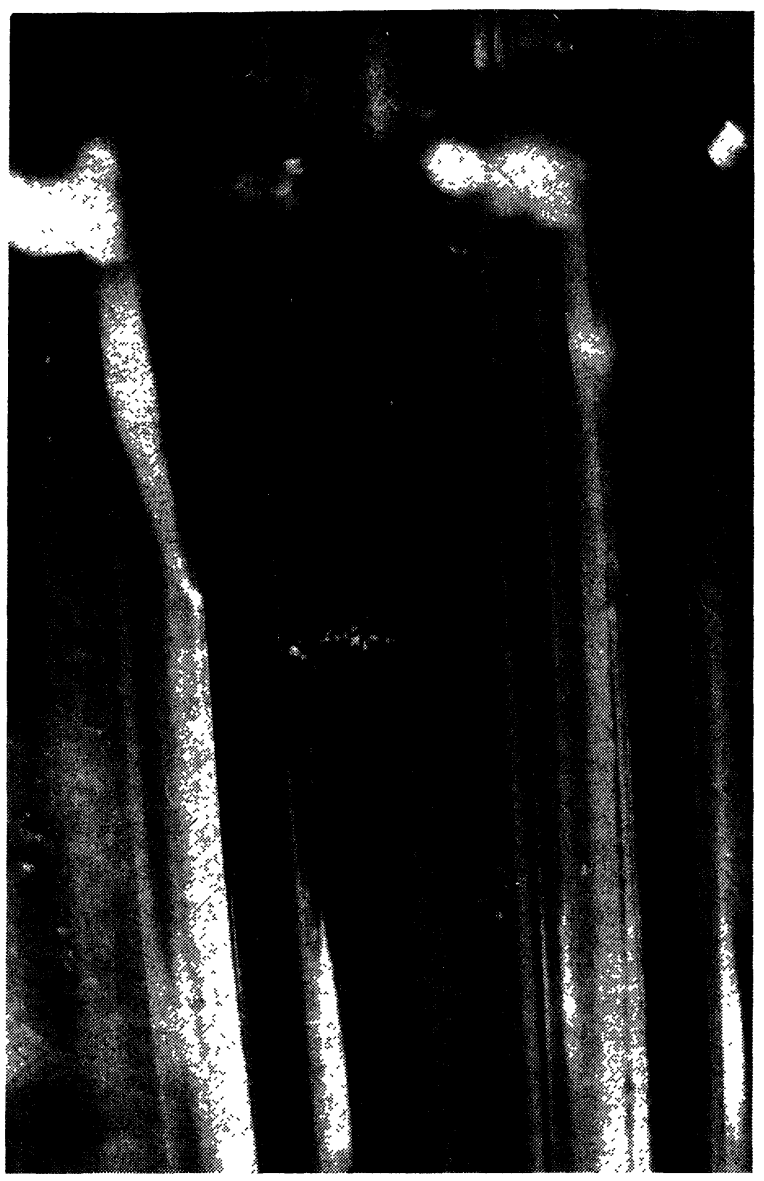

FIG. 9. - Discharge tree inside the tube glass insulator (Heidelberg). The tree starts at an electrode and developed about $12 \mathrm{~mm}$ into the glass parallel to the field.

operated with radiation sources at the tank bottom at terminal voltages above 11 or $12 \mathrm{MV}$ to reduce tank spark rates. The permanent ionization of the tank gas seems to discharge dust particles while they move to the terminal. In general a total ionization current of about $50-100 \mu \mathrm{A}$ is maintained by either $192 \mathrm{Ir}$ or ${ }^{137}$ Cs sources. An unwanted side effect of the ionized tank gas is, however, a distortion of the column gradient near the terminal. This distortion was measured at Munich to be more than $10 \%$ with $4 \mathrm{Ci}$ of ${ }^{192} \mathrm{Ir}$ and leads to an extra stress of the tubes in the most critical region near the terminal.

4. Beam transmission. - Beam transmission through the Tandem is of some importance for several reasons. 1) There is increasing interest in exotic beams like ${ }^{48} \mathrm{Ca},{ }^{14} \mathrm{C}$ or other rare isotopes, where low yields of the ion source are common. 2) For a given target current high transmission leads to increased foil life times. 3) The part of the beam not transmitted might cause damage in the tube by sputtering effects and finally. 4) The Tandem might be used as injector for a post accelerator with additional beam losses due to stripping. In addition there is increasing interest in pulsed heavy ion beams with large beam losses due to limited phase acceptances.
The exact determination or comparison of transmissions is difficult because of the lack of information on charge distributions and average charge states. It is also necessary to relate the stated transmission to the low energy phase space acceptance used during the measurement.

Figure 10 presents some data collected at Strasbourg and at Munich at $10 \mathrm{MV}$ terminal voltage. Transmissions of 50 to $70 \%$ are also typical for Orsay and Heidelberg. The transmissions shown in the figure are measured from base to base. For their determination only average charge states must be known. The Strasbourg data indicate a dependence on the type of ion source used. The sputter source is a Mark II UNIS-source of Extrion. The Munich data (dashed lines) were measured with a HICONEX $834\left(^{1}\right)$. It turns out that the beam of this source fits nicely into the standard acceptance of the MP Tandem $(2.5 \mathrm{~mm} \times 7 \mathrm{mrad} \times \pi$ at the injection aperture $)$ if the cone is in good shape and the Cs-beam focussed properly.

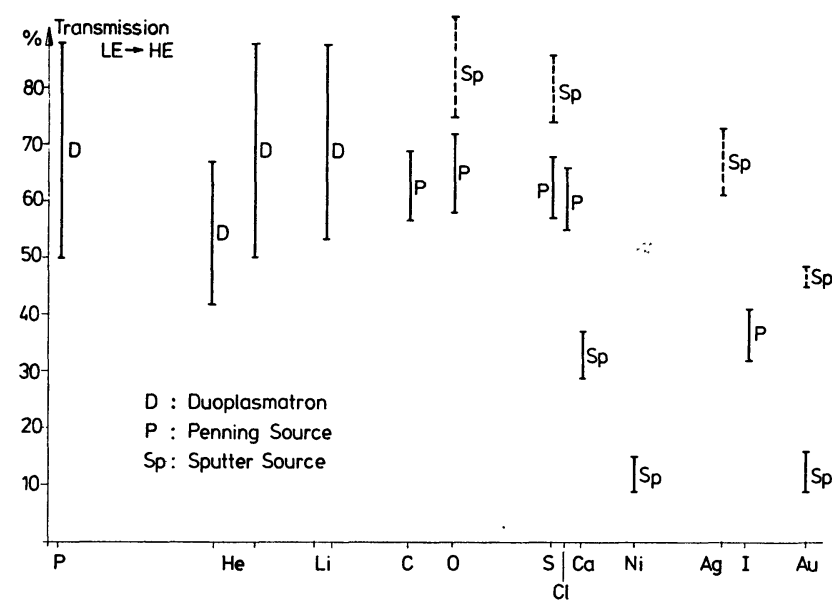

FIG. 10. - Base to base heavy ion beam transmissions through MP-10 Strasbourg (dashed lines: MP-8 Munich). The transmission is effected by the emittance of the ion source. These data were obtained without using a terminal lens.

At Munich the low energy acceptance is defined by a system of three variable apertures as shown in figure 11. This device proved to be extremely useful since it allows a reproducable beam transport through the whole system. It is also useful to reduce the beam intensity to the value needed for the experiment.

More important than the base to base transmissions are the ones for a given charge state behind the analysing magnet. In figure 12 some data on gold are plotted as a function of the stripper foil thickness. They were obtained at Munich. The very good transmission for the thin foil is due to a number of measures which were part of the conversion programme of the Munich Tandem: 1) no grid at the tube entrance, 2) extremely good vacuum, near $10^{-8}$ torr, 3 ) terminal lens adjusted to optimize the particular charge state and 4) several steerers to compensate for small misalignments of lenses etc.

( $\left.{ }^{1}\right)$ Manufactured by GIC. 

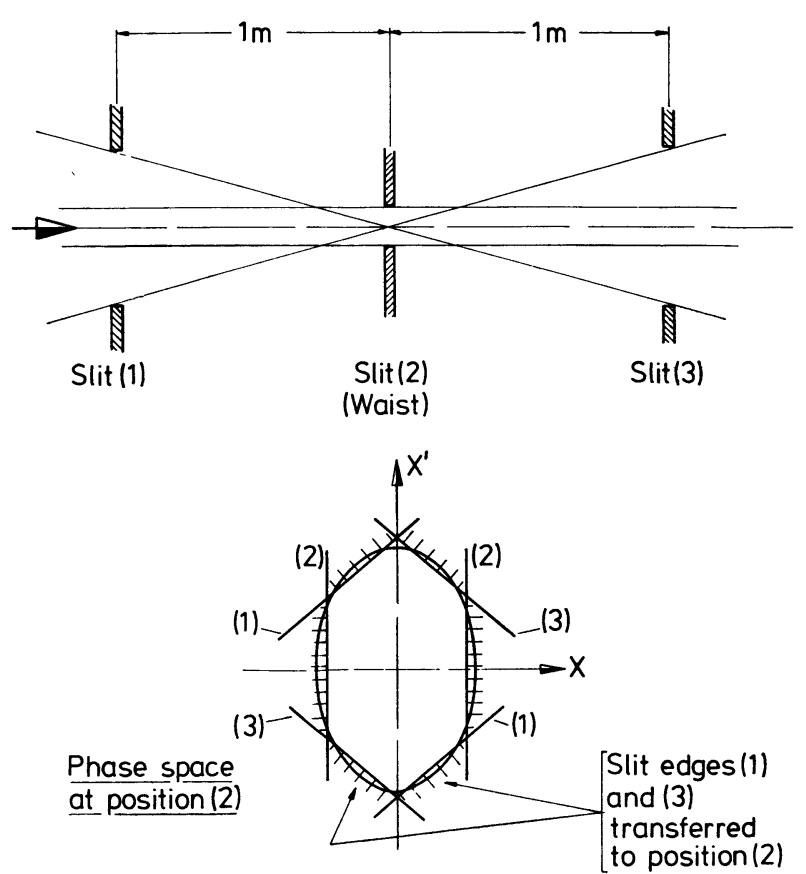

FIG. 11. - Definition of the low energy acceptance of MP-8 Munich by three symmetrically arranged variable apertures. Divergence and size of the waist at the central aperture can be varied.

To evaluate the transmission in figure 12 from the measured analysed beam currents the charge fractions used $(5.7 \%$ and $6 \%$ respectively) were slightly higher than the ones interpolated from data found in the literature [4]. The latter ones $(4 \%$ and $5 \%$ ) would lead to even better or unrealistic values for the transmissions. The corrections were based on separate observations.

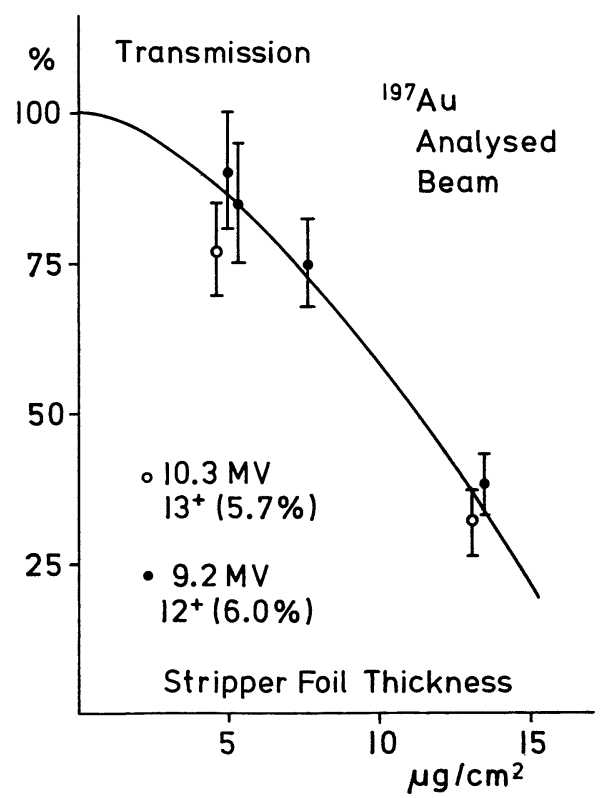

FIG. 12. - Transmission of a gold beam as a function of foil thickness. (MP-8 Munich). The data were obtained by optimizing the terminal lens for the particular charge state. For thicker foils the transmission is limited by the high energy acceptance due to multiple scattering.
The effect of the terminal lens can be demonstrated with the help of figure 13. The beam leaving the high energy side of the accelerator was passed through a $100 \mu \mathrm{g} / \mathrm{cm}^{2}$ gold foil. Scattered particles are detected by a solid state counter at $30^{\circ}$. The spectra are corrected for the energy dependence of the Rutherford cross section. Since gold was scattered on gold the resolution of the detection system suffers from kinematic effects. The comparison of charge state distributions with and without terminal lens indicates that the relative intensity of the $12^{+}$state of a gold beam at $10.3 \mathrm{MV}$ is increased by a factor of 2.5 if the terminal lens is optimized properly.

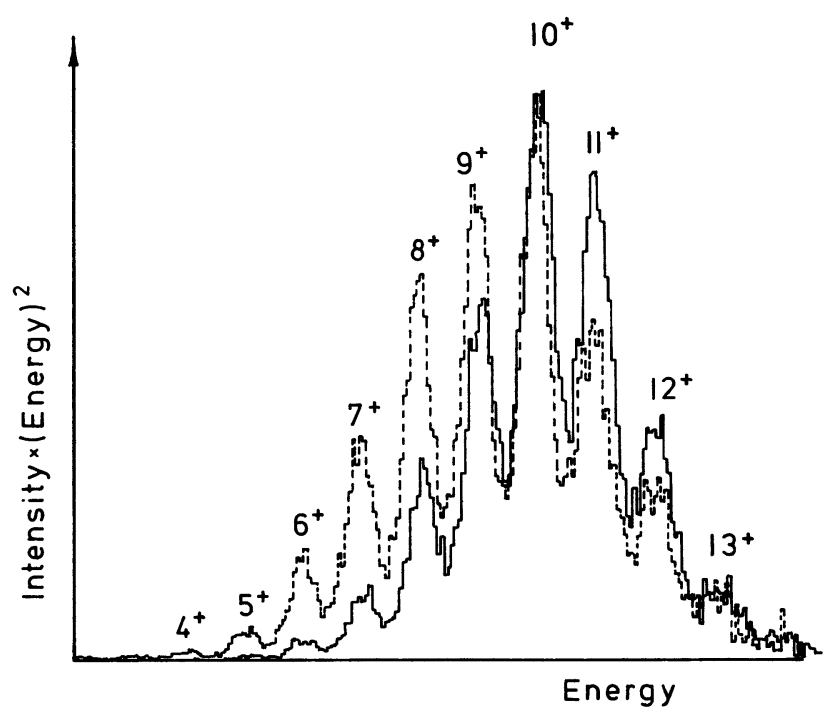

FIG. 13. - Effect of the terminal lens on the charge state distribution of a gold beam at $9.2 \mathrm{MV}$ terminal voltage. The lens is set for the $12+$ beam. Full: with terminal lens, dashed: without terminal lens. See text for details.

5. The Munich Conversion. - Since the upgrading of the Munich MP is somewhat unique due to the use of NEC tubes, some more details about this machine are presented in the following section.

Some special components developed during the upgrading program are discussed in separate papers contributed to these proceedings (D2, D6, D7, H7 and $\mathrm{H} 8$ ).

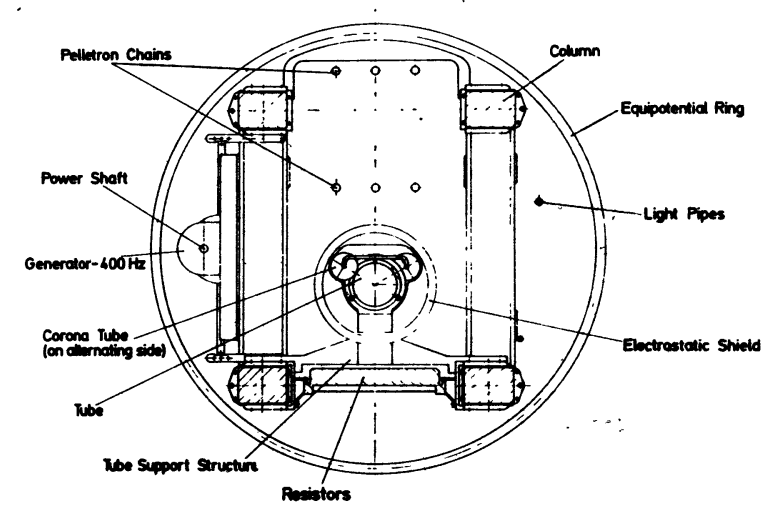

FIG. 14. - Cross section of the column of the converted MP-8 Munich. 


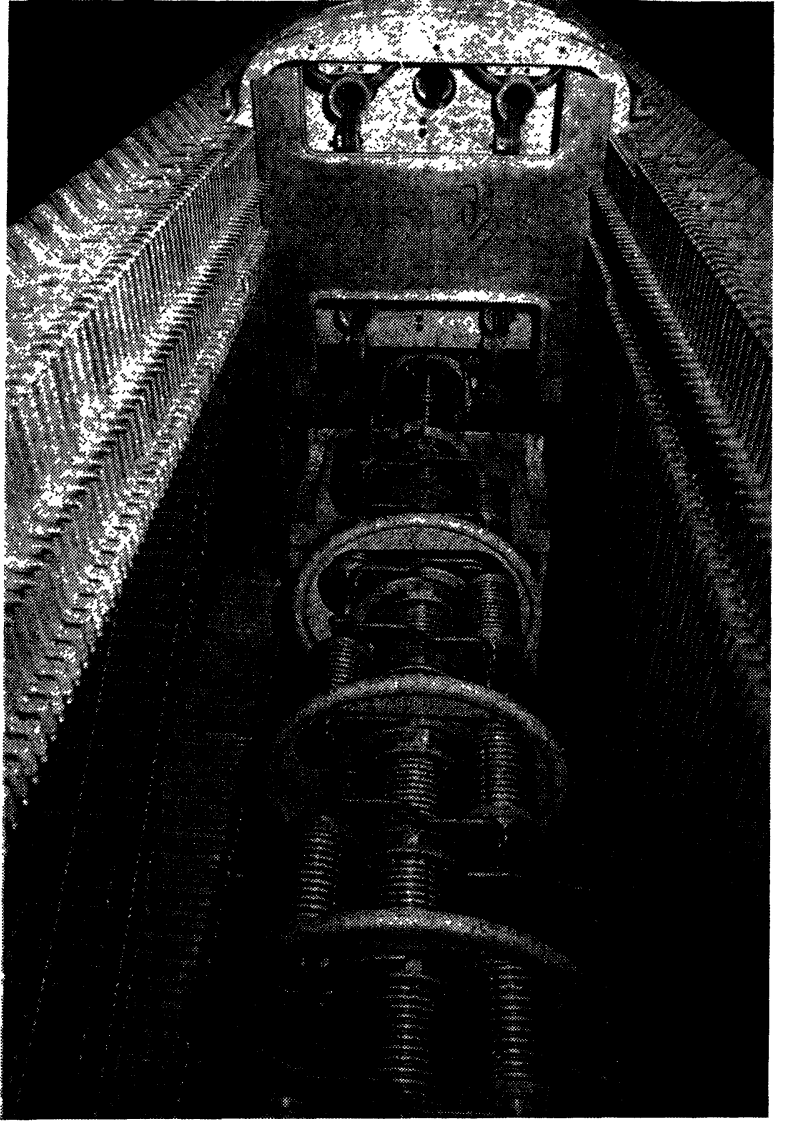

FIG. 15. - View onto the tubes with corona tubes on alternating sides and support elements, MP-8 Munich. The charging chains, vertical rods (partly) and equipotential rings are removed.

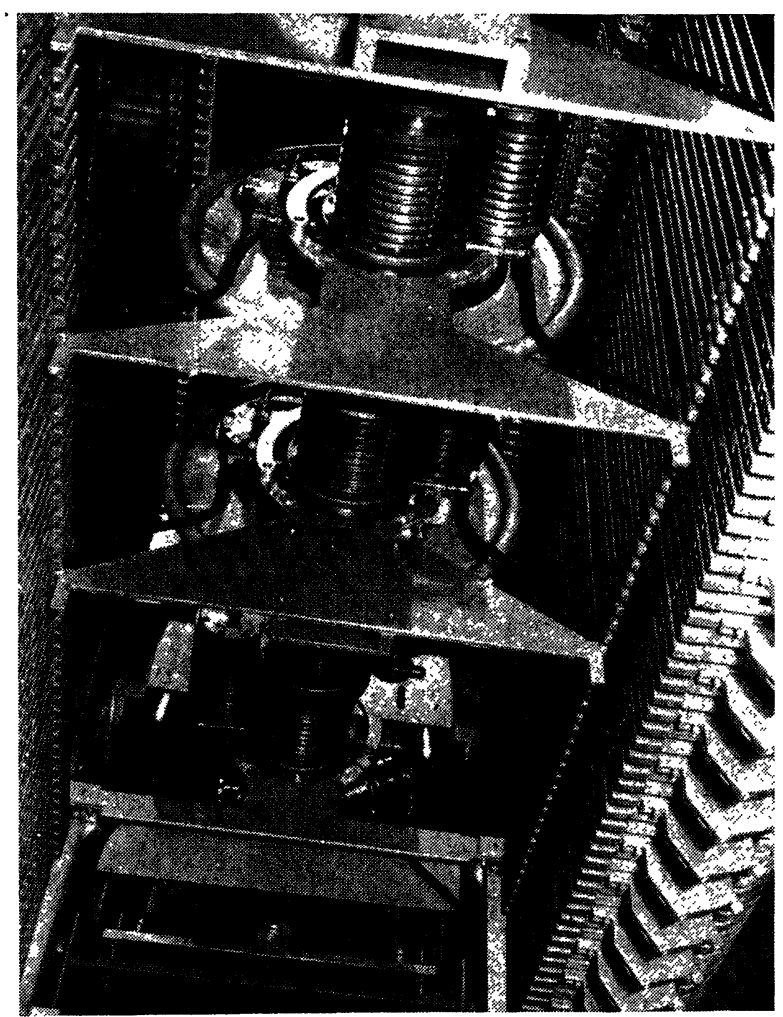

Fig. 16. - Acceleration tubes seen from below. The support elements are mounted to the lower column members. Resistors and equipotential rings removed.
Figure 14 shows the cross section of the column indicating the position of the tube relative to the Pelletron chains, the corona tubes which are mounted directly on alternative sides of the tube, the bundle of light pipes, the power shaft, and the column resistors.

The figures 15-19 show some photos of the tubes

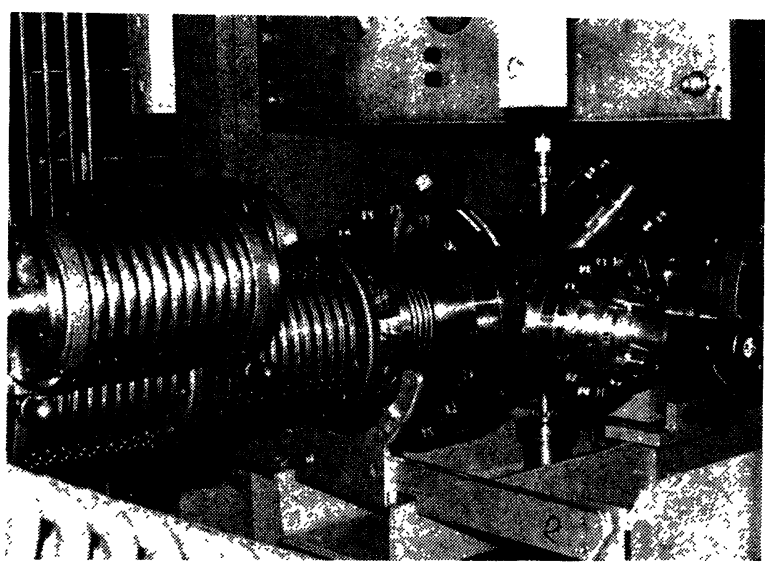

Fig. 17. - Low energy tube entrance with bellow, Faraday cup, and variable divided aperture.

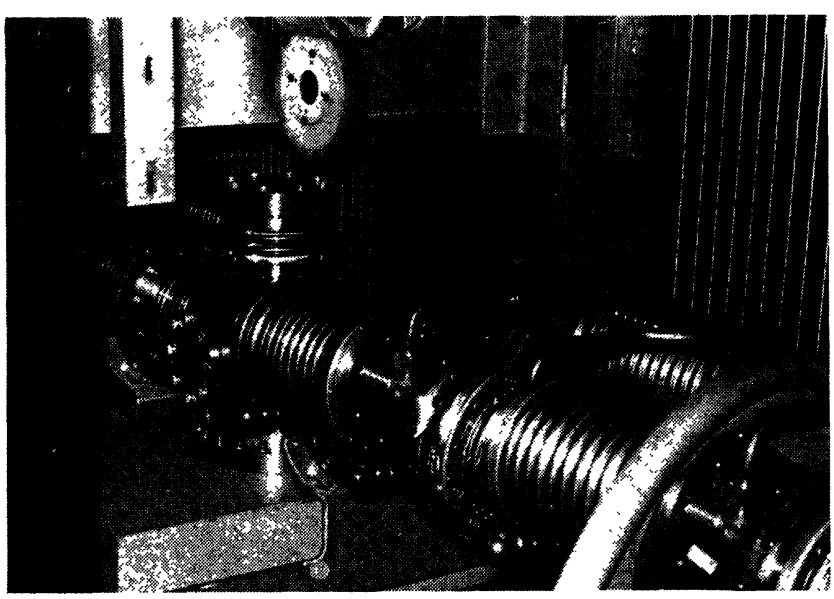

Fig. 18. - Dead section pumping cross. The pump is magnetically shielded by a steel cover. Above: insulated support of the shielded aperture (see also Fig. 22).

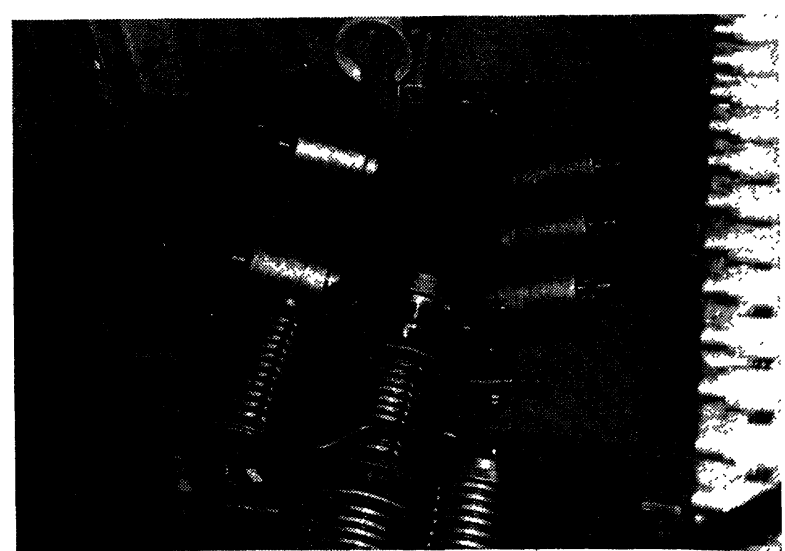

Fig. 19. - Electrostatic triplet (mid column lens) in the 2. dead section of the low energy column. The covers of the annular spark gaps at the feedthroughs and connecting cables removed. 
and other components inside the column. The tubes are supported three times between dead sections. There are pumps and shielded, back-biased apertures in all dead sections. At the low energy tube entrance a Faraday-cup and a variable aperture are installed. All components are bakable, all seals aluminium wire.

If.NEC tubes are combined with an HVEC column a separate potential grading for tubes and column must be employed. 11 tube insulators of $0.5^{\prime \prime}$ correspond to 7 column insulators of $1^{\prime \prime}$. At Munich NEC corona tubes are employed for the tube grading while HVEC high gradient resistors are used for the column. The diagram of figure 20 explains somewhat the features of such a combination. The total column current is plotted against the voltage across one $20 \mathrm{~cm}$ NEC tube section. The rated voltage of the tube is $333 \mathrm{kV}$. At this gradient the resistor current is $60 \mu \mathrm{A}$. If at an arbitrarily selected voltage of about $200 \mathrm{kV}$ a total current of $75 \mu \mathrm{A}$ is chosen by arranging the proper $\mathrm{SF}_{6}$ pressure in the corona tubes, the corona current will be about $40 \mu \mathrm{A}$. The sum of the resistor current $I_{\mathrm{R}}$ and the corona current $I_{\mathrm{C}}$ must be constant for the whole column. If - due to variations in the needle burndown - the corona characteristics vary as shown schematically, the tube voltages will vary accordingly. The steep characteristic of the corona needles corresponds to an effective resistance of only about $1 / 5$ of that of the resistors and is contributing to the stability of the machine if the total current varies because of upcharge variations or gradient disturbancies.

The column resistors (2) were equipped with a common spark gap for improved protection (Fig. 21).

A very important part of the beam transport through the tubes are the dead section apertures. They are shown schematically on figure 22 . The apertures confine the beam to about $20 \mathrm{~mm}$, while the size of the tube apertures is $25 \mathrm{~mm}$. Beam loading is avoided if

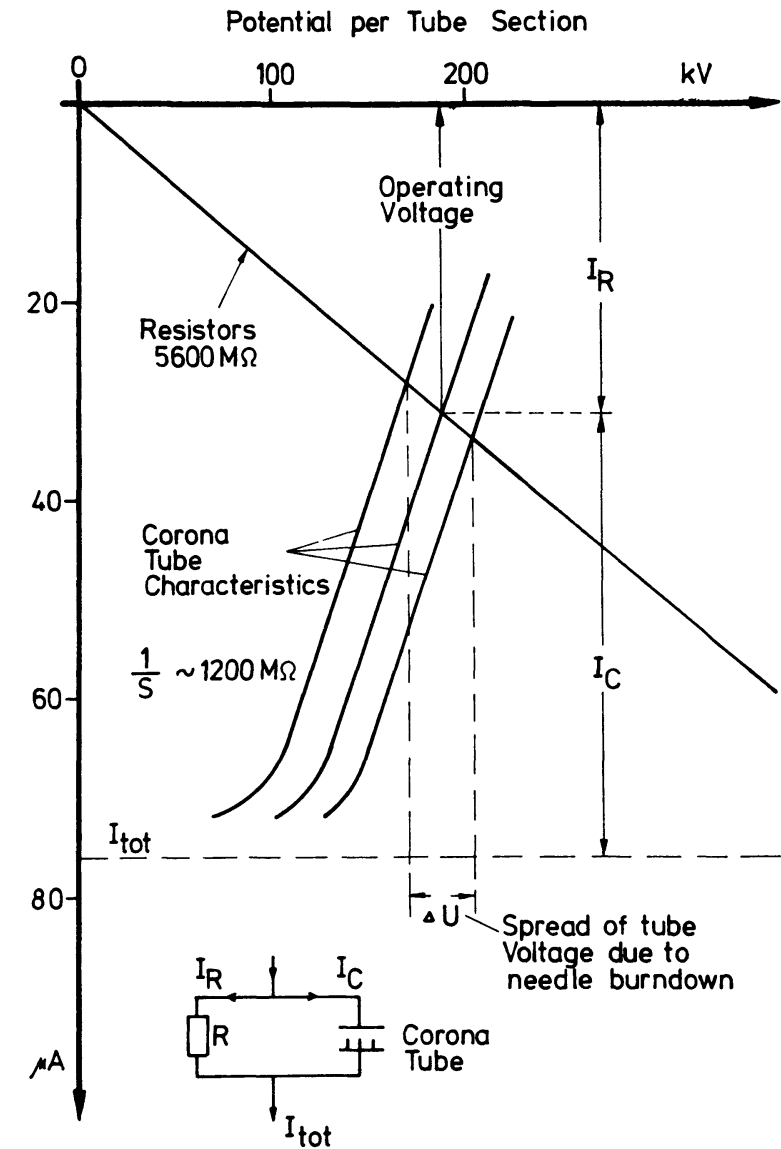

FIG. 20. - Illustration of the parallel connection of corona tubes and column resistors, schematically. Due to the variations of the needle burn down a small fluctuation of the gradient is expected. The relatively steep characteristic of the corona stabilizes the gradient against variations of the total current $I_{\text {tot }}$.

the beam does not hit tube electrodes. The upstreaming electrons from residual gas interactions are slowed down in low $Z$ material (special graphite). The back bias voltages are taken from the column resistors

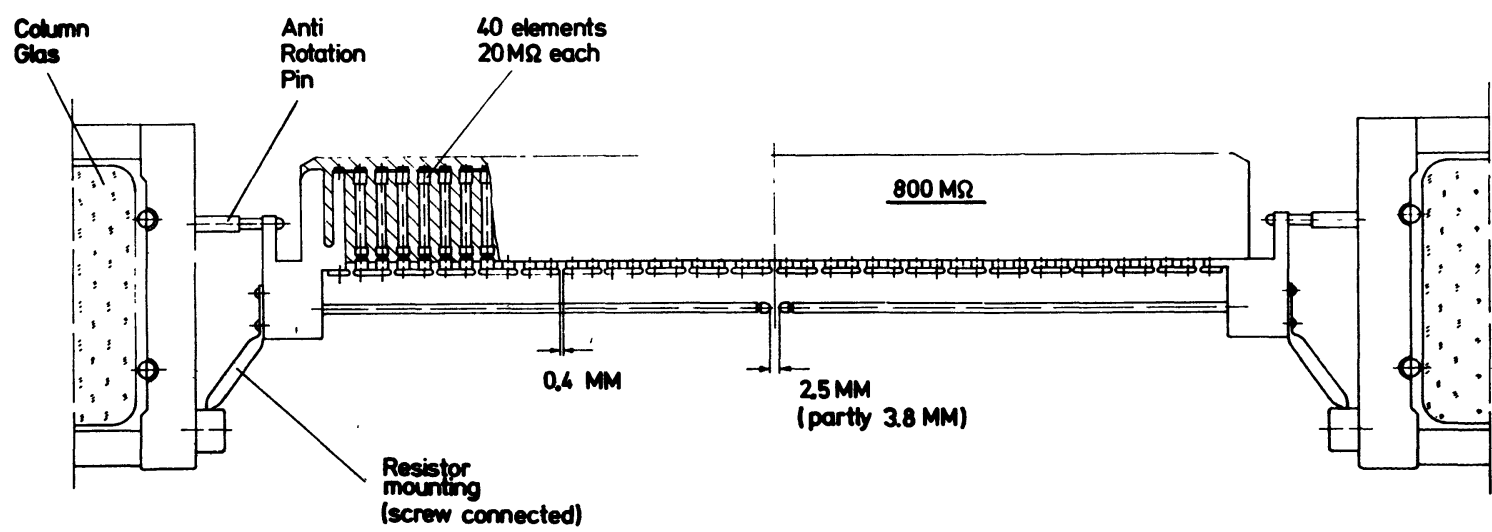

FIG. 21. - 40-element column resistors, manufactured by HVEC with specially designed mounting system and common protection spark gap.

(2) Manufactured by HVEC. 


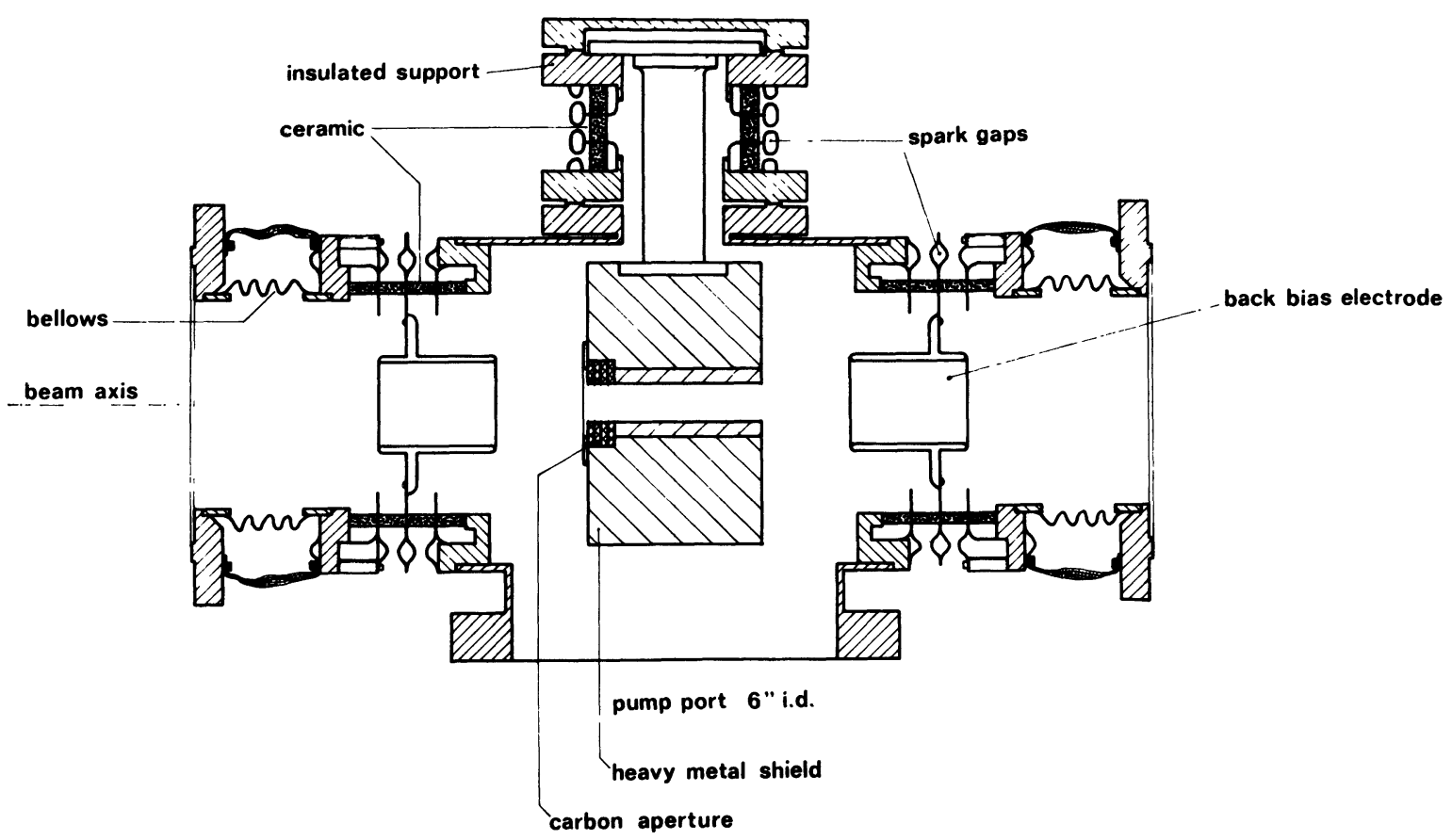

FIG. 22. - Dead section cross, designed at Munich, manufactured by NEC, with shielded aperture. Electrons produced by residual gas interactions of the beam would come from the left. X-ray production is reduced by the low- $Z$ insert. X-rays are absorbed by heavy metal. The aperture is suppressed electrostatically.

with proper protection by spark gaps and serial resistors. The current on the apertures can be measured through the telemetric system, which is described in the contribution D6 to these proceedings.

With this arrangement no beam loading was observed even at 8-10 $\mu \mathrm{A}$ of ${ }^{32} \mathrm{~S}$ injected. Charge selection in the terminal turns out to be not necessary. No magnetic suppression is employed.

In contrast to the very good beam properties the voltage performance of the converted MP at Munich has been disappointing so far. Based on the number of NEC tube modules installed, a terminal voltage of 13.3 MV was expected and guaranteed. However, a maximum voltage of only $12.8 \mathrm{MV}$ was reached for a short time during conditioning and experiments are at the moment not possible above about $11 \mathrm{MV}$. The limitation is caused by very excessive tube activities similar to conditioning effects and by a prohibitively high tube spark rate. These effects show practically no improvements upon tube conditioning. They were traced back as being at least partly due to organic contaminations introduced by the packing method before shipment. It is possible that other chemical materials and micro-particles originating from certain steps of the manufacturing process are also contributing to the difficulties.

The examination of some of the tubes showed signs of violent micro-discharges between the electrodes with electrode material sputtered onto the insulator surfaces, traces from surface flash overs, extensive discolorings of the metal surfaces, as well as clumps of molten metal. Figures 23-25 illustrate some of the observations. Not all details of the effects of the contaminations are understood but they seem to fit well into the current pictures of insulator breakdown, micro-discharges, clumps, and microparticles as des-

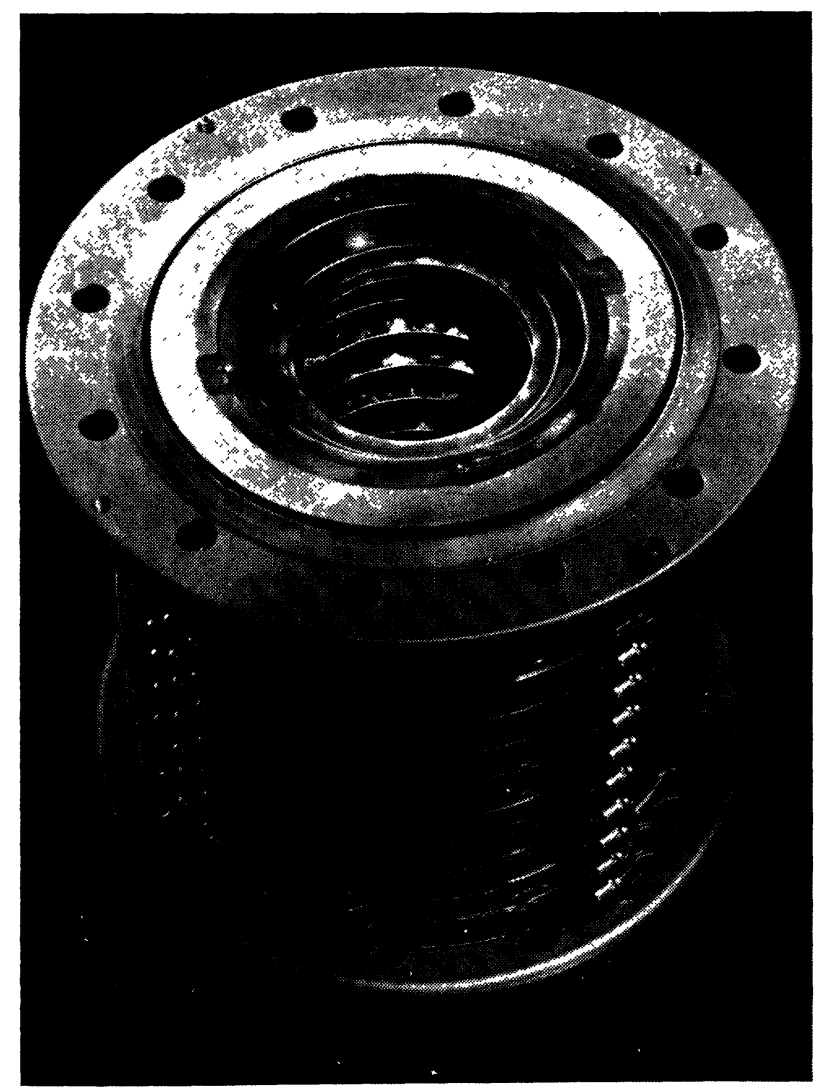

Fig. 23. - NEC-tube removed from MP-8 Munich. Due to discharges caused by organic contaminations, the electrodes are chemically discolored. Shiny regions from sputtering. 
cribed by Hyder in contribution F1 to these proceedings.

A layer of any sticky organic compounds on the electrode and insulator surfaces represents a large reservoir of molecules which is readily available to feed and support a discharge between electrodes, particularly along the insulator surface. As illustrated by figure 26 there exists a certain unprotected region which is due to the finite time necessary to develop a discharge between the spark gaps. If breakdowns inside the tube are faster than those of the protection spark gap, large amounts of energy will be deposited within the interior of the tube. Molecules available on the insulator surface might conceivably allow such fast flashovers.

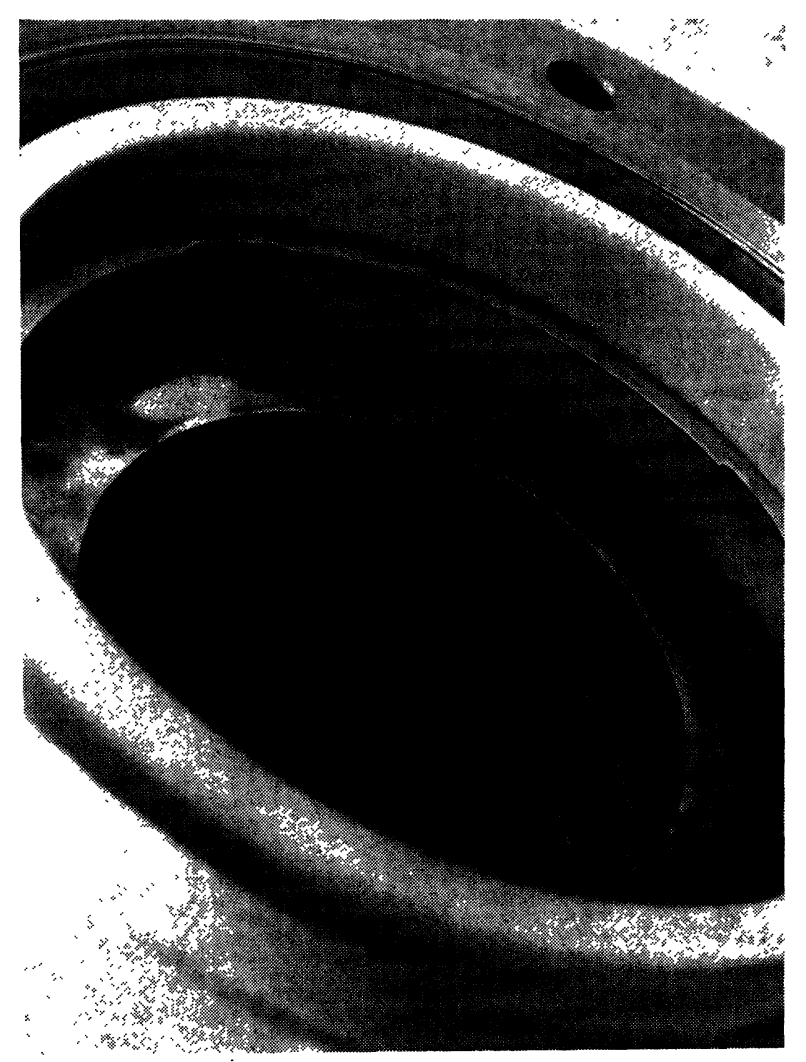

FIG. 24. - Insulator surface covered with sputtered electrode material (gray regions on the ceramic ring).

As a first step to try to remove the contaminations the tubes and most of the other vacuum components inside the tank were baked at about $100^{\circ} \mathrm{C}$. Some of the tubes, which were believed to have undergone more damages than the other ones, were replaced.

However, the sputtering damages in the rest of the tubes and contaminations not removed by baking are apparently still limiting the voltage holding capability below specifications. Also, the corona tubes have suffered unusually due to the heavy discharges in the acceleration tubes.

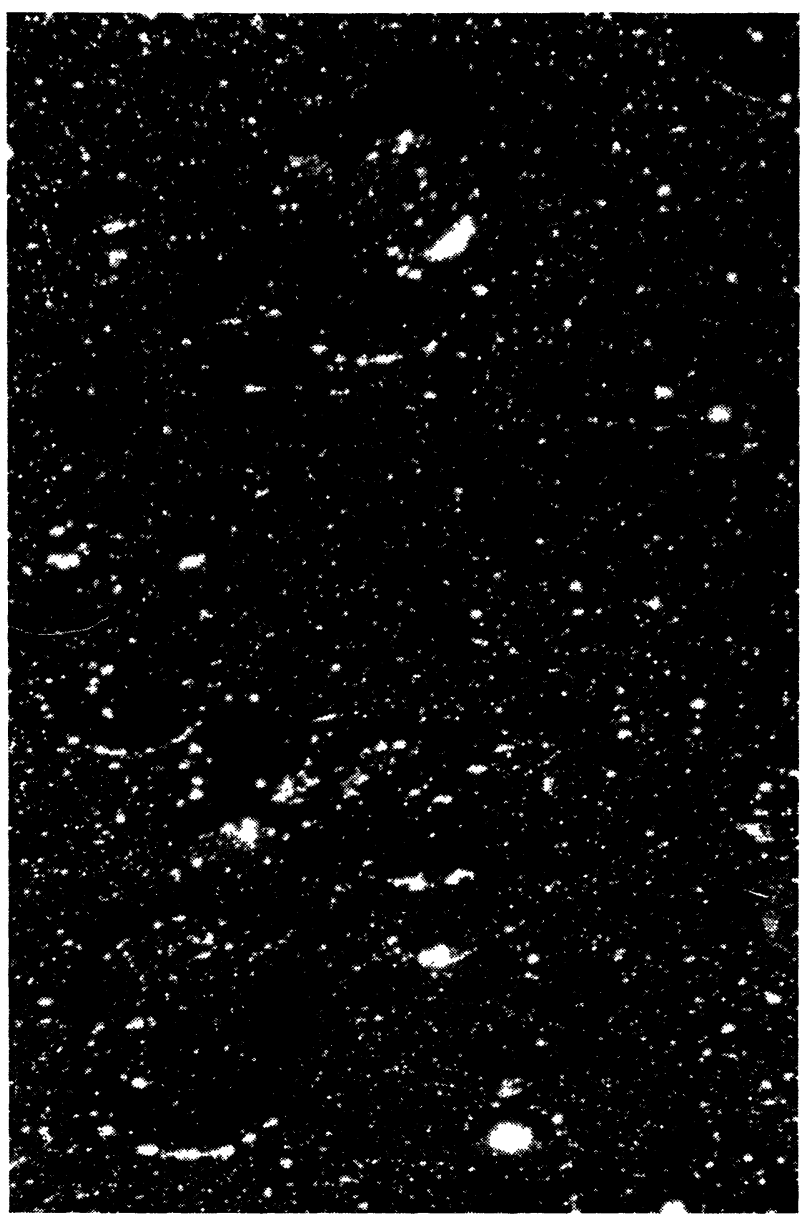

FIG. 25. - Micro-photo of clumps of molten metal thrown onto an aperture surface. Edges of the small metallic discs (about $0.3 \mathrm{~mm}$ diameter, mass possibly about $1 \mu \mathrm{g}$ ) apparently bent upwards by electrostatic forces.

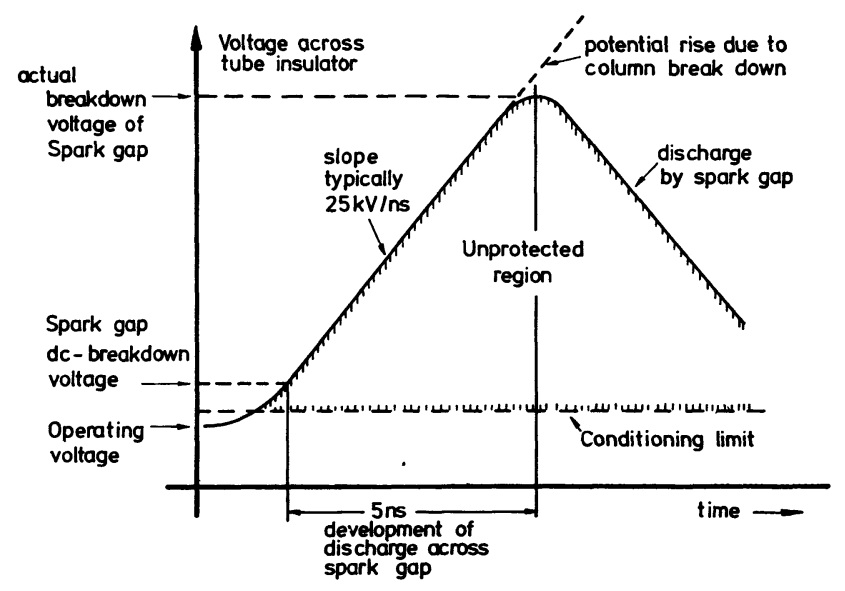

Fig. 26. - Very schematic illustration of the voltage transient appearing at a tube insulator after a spark somewhere in the accelerator. The overvoltage is due to the slow development of the protecting spark channel across the spark gap. If fast discharge mechanisms inside the vacuum are possible, the tube might suffer damages (unprotected region). 
Large variations in needle burn down or even evaporated needles do not provide a smooth voltage grading necessary for statisfactory tube performance. The damages of the corona needles are clearly a consequence of the poor tube performance caused. by the contaminations.

Based on the experience collected and the many observations and tests carried out to solve the voltage problem it is now felt at Munich that the attainment of the guaranteed terminal voltage should be no problem after additional replacements of acceleration tubes and repairs of the corona tubes. Indications of more fundamental problems could not be determined.
Acknowledgements. - I would like to thank the colleagues at the european Tandem laboratories for making their operating data and other interesting informations on their machines available, especially Drs. M. Letournel, M. Langevin and R. Repnow. My colleagues at Munich, particularly Drs. H. Münzer and L. Rohrer, Mr. W. Assmann, and Mr. W. Goldstein have contributed valuable informations for this paper. In connection with the Munich tube problem I had stimulating discussions with Drs. D. A. Eastham, Ch. H. Goldie, R. G. Herb, H. R. Mck. Hyder, A. Isoya, Ch. M. Jones, T. Joy, K. Purser, H. E. Wegner and J. L. Yntema.

\section{References}

[1] Aitken T. W., private communication and Daresbury Newsletter Nr. 28, july 1976

[2] Rabinowitz I. I., International Conference on Electrostatic Accelerator Technology (1973) 197.

[3] Assmann W., Münzer H., Rohrer L. and Skorka S. J., Nucl. Instrum. Methods. 137 (1976) 19.

[4] Betz H. D., Rev. Mod. Phys. 44 (1972) 465.

[5] Assmann W., et al., Nucl. Instrum. Methods. 122 (1974) 196. 